http://jmscr.igmpublication.org/home/

ISSN (e)-2347-176x ISSN (p) 2455-0450

crossref DOI: https://dx.doi.org/10.18535/jmscr/v7i7.70

Journal Of Medical Science And Clinical Research

\title{
Vitamin D Deficiency in Pregnancy: Does Magnesium Play any Role?
}

\author{
Authors \\ Sanchayan Sinha ${ }^{1}$, Souvik Konar ${ }^{2}$, Sayantan Dasgupta ${ }^{3}$, Soma Gupta ${ }^{4}$ \\ ${ }^{1}$ Junior Resident, Department of Biochemistry, NRS Medical College, Kolkata \\ ${ }^{2}$ Senior Resident, Department of Biochemistry, NRS Medical College, Kolkata \\ ${ }^{3}$ Assistant Professor, Department of Biochemistry, NRS Medical College, Kolkata \\ ${ }^{4}$ Professor \& Head, Department of Biochemistry, NRS Medical College, Kolkata \\ Institute: Nil Ratan Sircar Medical College. Department of Biochemistry, \\ 138 A.J.C Bose Road, Kolkata- 700014, India \\ *Corresponding Author \\ Soma Gupta \\ Address: 40A, Simla Street. Kolkata 700006, India
}

\begin{abstract}
Introduction: Vitamin D is very important for fetal skeletal development in pregnancy. Deficiency of Vitamin $D$ is quiet common among the pregnant women in our country. In the pathway of Vitamin D metabolism, magnesium is known to play an important role. It is cofactor of many enzymes involved in vitamin D metabolism \& vitamin D binding protein. Some studies have suggested that both vitamin D and magnesium level decreases during pregnancy with adverse feto-maternal outcome.

Aims \& Objectives: To find out levels of serum magnesium \& vitamin D in both pregnant \& non pregnant women \& compare their levels for any significant difference \& to find out whether any correlation exists between magnesium level and vitamin D level in pregnancy.

Materials \& Methods: The study included the estimation of serum magnesium \& vitamin D of 100 pregnant women (cases) \& 100 age matched non pregnant women (controls). The values were tabulated \& analysed by standard statistical method.

Result: Serum magnesium level was found to be lower in pregnancy (Mean $\pm S D$ is $1.83 \mathrm{mg} / \mathrm{dl} \pm 0.61$ ) than in non pregnant women (Mean $\pm S D$ is $1.94 \mathrm{mg} / \mathrm{dl} \pm 0.64$ ). Butthe decrease was not found to be significant ( $p<$ 0.05). However serum Vitamin D level was also found to be decreased in pregnancy (Mean $\pm S D$ is 14.74 $\mathrm{ng} / \mathrm{ml} \pm 5.83$ ) than in non pregnant (Mean $\pm S D$ is $21.19 \mathrm{ng} / \mathrm{ml} \pm 7.82$ ) and the decrease was found to be significant $(p<0.05)$. Correlation coefficient between magnesium \& Vitamin D was found to be 0.355 .

Discussion: The decrease in Vitamin D level was found to be positively correlated with decrease in magnesium level in pregnancy. However the correlation coefficient is too small to establish any concrete correlation between them. Further in depth study is required to find out the cause of Vitamin D deficiency in pregnant women.
\end{abstract}

Keywords: Vitamin D, Magnesium, Pregnancy, Antepartum haemorrhage, Low birth weight, Birth asphyxia.

\section{Introduction}

Vitamin D is an essential fat soluble vitamin \&a prohormone derived from cholesterol. It is produced in our skin with exposure to the ultraviolet rayof sunlight. It plays very important role in metabolism of calcium and phosphate \& their homeostasis in our body. ${ }^{(1)}$ 
During pregnancy and lactation, mother requires significant amount of calcium to pass onto the developing fetus and to the suckling neonate after delivery respectively. It is essential for musculoskeletal development. ${ }^{(2)}$

During gestation, the human fetus requires $30 \mathrm{~g}$ Calcium on average, of which $99 \%$ is contained within the skeleton. More than $150 \mathrm{mg} / \mathrm{kg}$ of this calcium is actively transferred each day across the placenta during the third trimester. ${ }^{(3,4)}$

The nutritional demand for vitamin $\mathrm{D}$ is more in pregnancy.Vitamin D deficiency in pregnancy has been reported to cause adverse fetomaternal outcome like preeclampsia, IUGR, impaired glucose tolerance, impaired bone development with suboptimal bone density \& rachitic changes. There isincreased chance of neonatal hypocalcemic seizure in the deficiency of Vitamin D. ${ }^{(5)}$ Magnesium is an abundant intracellular ion and an essential element for fetal well-being. Its deficiency during pregnancy has been seen to be associated with eclampsia, preeclampsia, preterm births, increased maternal hospitalization, incidence of low birth weight and small for gestational age infants. ${ }^{(6,7)}$

Magnesium acts as cofactor of various biochemical reactions including those involved in the Vitamin D metabolic pathway. In pregnancy its demand increases for the growth and development of the fetus. Increased renal excretion of magnesium is due to $25 \%$ increase in glomerular filtration rate in pregnancy. ${ }^{(8,9)}$

Magnesium acts as cofactor in the synthesis of vitamin $\mathrm{D}$ binding protein, parathormone, 25(OH)D, and 1,25(OH)2D. ${ }^{(8)}$

Decreased magnesium intake causes decrease inthe availability of $1,25(\mathrm{OH}) 2 \mathrm{D}$, synthesis of $25(\mathrm{OH}) \mathrm{D}$ and $1,25(\mathrm{OH}) 2 \mathrm{D}$ and decrease the transfer to target tissues by Vitamin D binding protein.

\section{Aims \& Objectives}

To find out levels of serum magnesium \& vitamin D in both pregnant \& non pregnant women \& compare their levels for any significant difference
$\&$ to find out whether any correlation exists between magnesium level and vitamin $\mathrm{D}$ level in pregnancy.

\section{Materials \& Methods}

This observational case control study was done in the Department of Biochemistry with joint collaboration of Department of Obstetrics \& Gynaecology of Nil RatanSircar Medical College from January 2017 to December 2017 after taking institutional ethical clearence. Total 100 pregnant women from the antennal OPD were taken as cases \& 100 age matched non pregnant women were taken as controls.

Pregnant women with gestational hypertension, gestational diabetes mellitus, pre-existing heart disease, renal impairment \&any musculoskeletal disorders were excluded from the study.

An amount of $5 \mathrm{ml}$ of blood sample was collected after 8 to 10 hours' fast in clotted vial. Serumwas separated \& stored in ultra freezer. The samples were analysed within 7 days of collection.

Serum magnesium was estimated for both cases \& controls by Calmagite method using semi auto analyzer. Serum vitamin D was estimated for both cases \& controls by ELISA method

The data was tabulated $\&$ analysed using standard statistical method (SPSS 20)

\section{Results}

Serum magnesium \& serum Vitamin D level of both pregnant (taken as cases) and nonpregnant (taken as controls) women has been given in table 1. Serum magnesium level was found to be lower in pregnancy than in non pregnant women. However the decrease was not found to be significant $(p<0.05)$. Serum Vitamin D level was also found to be decreased in pregnant than in non pregnant and the decrease was found to be significant $(\mathrm{p}<0.05)$. The comparison of the levels of two parameters are also shown in Figure 1 .

Statistically significant positive correlation was found between serum magnesium \& serum Vitamin D $(r$ value $=+0.355 \&$ p value $=0.018)$ 
Table 1

\begin{tabular}{|l|c|c|c|}
\hline Parameter & $\begin{array}{c}\text { Cases } \\
((\mathrm{Mean} \pm \mathrm{SD})\end{array}$ & $\begin{array}{c}\text { Controls } \\
(\text { Mean } \pm \mathrm{SD})\end{array}$ & P value \\
\hline Magnesium $(\mathrm{mg} / \mathrm{dl})$ & $1.83 \mathrm{mg} / \mathrm{dl} \pm 0.61$ & $1.94 \mathrm{mg} / \mathrm{dl} \pm 0.64$ & $\mathrm{p}=0.546$ \\
\hline Vitamin D $(\mathrm{ng} / \mathrm{ml})$ & $14.74 \mathrm{ng} / \mathrm{ml} \pm 5.83$ & $21.19 \mathrm{ng} / \mathrm{ml} \pm 7.82$ & $\mathbf{p}=\mathbf{0 . 0 0 2}$ \\
\hline
\end{tabular}

Fig.1: Comparison of serum magnesium\&Vitamin Dbetween cases and controls

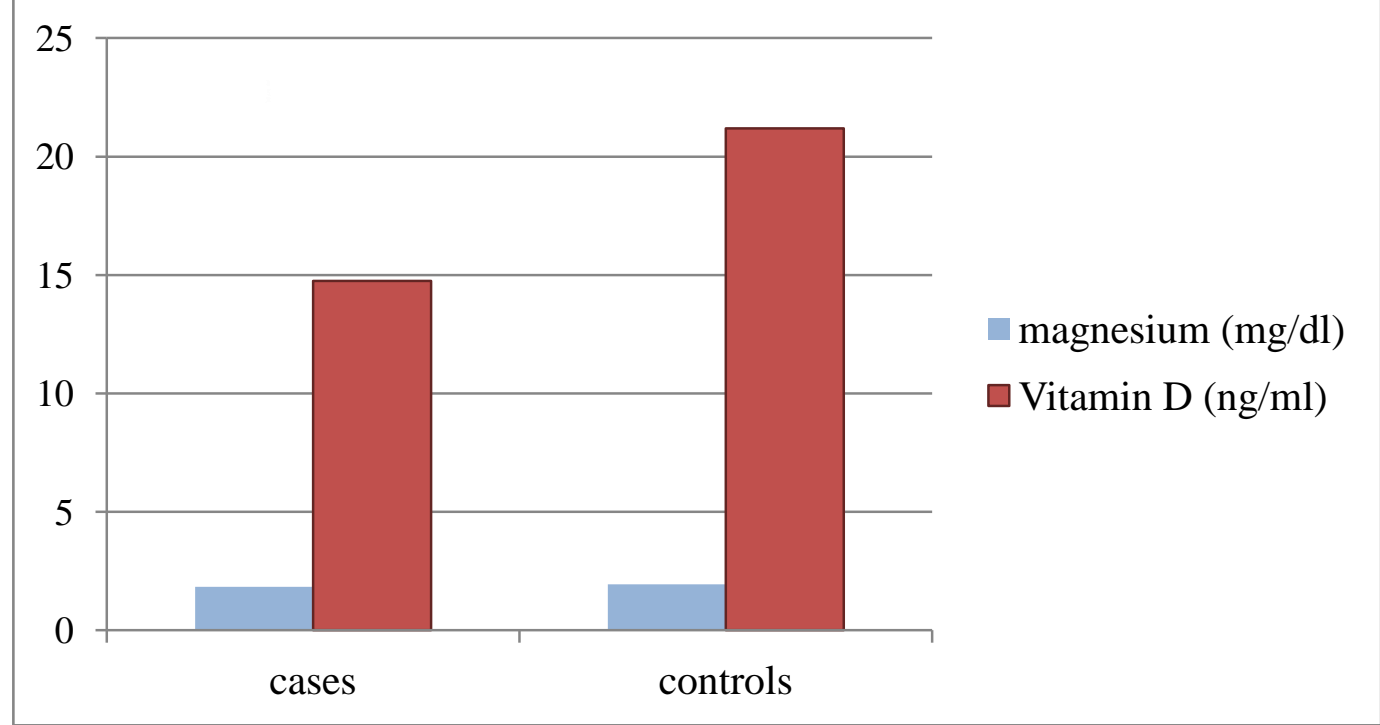

\section{Discussion}

Vitamin D and its active metabolite 1,25dihydroxyvitamin $\mathrm{D}(1,25(\mathrm{OH}) 2 \mathrm{D})$ have classical actions on calcium balance and bone metabolism. Without sufficient $1,25(\mathrm{OH}) 2 \mathrm{D}$, the intestine cannot absorb calcium and phosphate adequately, which can lead to secondary hyperparathyroidism and a lack of new bone mineralisation. Rickets is a childhood vitamin D insufficiency and usually develops some months after delivery. However, the neonate is at risk of hypocalcaemictetany consequent to maternal hypovitaminosis $\mathrm{D} .^{(1,2)}$

In pregnancy, micronutrients including magnesium are important for normal growth and development of baby. Deficiency of magnesium in mothers can impact not only the health of mother but their babies too. The formation of new tissue (maternal and fetal) during pregnancy requires high magnesium intake than that of the normal nonpregnant women of comparable age. ${ }^{(8)}$

Magnesium acts as cofactor in the synthesis of VDBP, PTH, 25(OH)D, and 1,25(OH)2D. It is a very important cofactor for 25 hydroxylase enzyme in liver which converts vitamin $\mathrm{D}$ to $25(\mathrm{OH}) \mathrm{D}$. In kidney also magnesium is an important factor where $1,25(\mathrm{OH})_{2} \mathrm{D}$ is formed. Magnesium is also important in release of parathyroid hormone from parathyroid gland \& biosynthesis of Vitamin D binding protein in liver. $^{(9)}$

Magnesium helps in absorption of calcium by $1,25(\mathrm{OH})_{2} \mathrm{D}$ in intestine \& distribution of calcium in various organs like bones, teeth etc.

In the present study serum magnesium level was found to be lower in pregnancy than in non pregnant women (table 1). This finding is consistent with the study done by Takaya J. et al in 2006 where increased prevalence of magnesium deficiency in pregnancy was observed ${ }^{(10)}$.

In our study, serum Vitamin D level was found to be decreased in pregnancy than in non pregnant and the decrease was found to be statistically significant $(\mathrm{p}<0.05)$ (table 1 \&Fig 1). Similar finding have also been found in various other studies. In the study of Zittermann A et al in 2012 increased risk of vitamin D deficiency in pregnancy worsening the fetomaternal outcome was observed. ${ }^{(11)}$ In another study done by Rude RK et al in 2015, low serum concentrations of 1,25-dihydroxyvitamin $\mathrm{D}$ was observed in human 
with magnesium deficiency and intramuscular injection of vitamin D did not show any improvement of later. ${ }^{(12)}$

Statistically significant positive correlation has been found between serum magnesium \& serum Vitamin D in our study.In the study done by Aghajafari $F$ et al there is also significantly decreased level of Vitamin D in magnesium deficient pregnant women resulting adverse fetomaternal outcome. ${ }^{(13)}$

\section{Conclusion}

The decrease in Vitamin D level was found to be positively correlated with decrease in magnesium level in pregnancy. Magnesium deficiency in pregnancy, though was not found to be significant, but this being an important cofactor in Vitamin D metabolism, should be monitored in pregnancy along with level of vitamin D.

\section{Limitation\& Future scope}

The study is simple and the fetomaternal outcome was not studied in this study. But it opens the avenue to study these two parameters in pregnancy and find out fetomaternal outcome. The effect of supplementation of Vitamin D is also an important aspect for further study.

\section{Acknowledgement}

The authors acknowledge the help of Prof. Chandana Das, Head of the Department of Obstetrics \& Gynaecology, N.R.S. Medical College for her valuable suggestion, guidance and support.

\section{References}

1. Hollis BW. Vitamin D requirement during pregnancy and lactation. J Bone Miner Res 2007;22(2):39-44.

2. Yu CK, Sykes L, Sethi M, Teoh TG, Robinson S. Vitamin D deficiency and supplementation during pregnancy. ClinEndocrinol (Oxf) 2009;70:685-90.

3. Mahon P, Harvey N, Crozier S, Inskip H, Robinson S, Arden N, et al. Low maternal vitamin $\mathrm{D}$ status and fetal bone development: cohort study. J Bone Miner Res 2010;25:14-9.

4. Kovacs CS, Kronenberg HM. Maternalfetal calcium and bone metabolismduring pregnancy, puerperium and lactation. Endocr Rev 1997; 18:832-72.

5. Hyppönen E, Power C. Hypovitaminosis D in British adults at age $45 \mathrm{y}$ : nationwide cohort study of dietary and lifestyle predictors. American Journal of Clinical Nutrition2007;85:860-8.

6. Kapil, U., P. Pathak. P. Singh and C. Singh. Mothers of urban slums communities in Delhi: a pilot: study. Indian Pediatrics. 2002;39: 365-369.

7. Shaikh, M.K., B.R. Devrajani, A.A. Soomro, S.Z.A. Shah, T. Devrajani and T. Das. World Applied Sciences Journal. 2011; 12(10): 1803-06.

8. Takaya, J., F. Yamato and K. Kaneko. Possible relationship between low birth weight and magnesium status: from the standpoint of fetal origin hypothesis. Magnesium resistance. 2226; 19: 63-9.

9. De Swiet, M. The respiratory system. Chamberlain $G$ and Broughton Pipkin F (eds) Clinical Physiology in Obstetrics. Oxford: Blackwell Science Ltd. 1998;3:111-128.

10. Takaya, J., F. Yamato and K. Kaneko. Possible relationship between low birth weight and magnesium status: from the standpoint of fetal origin hypothesis. Magnesium resistant2006;19:63-9.

11. Zittermann A, Iodice S, Pilz S, Grant WB, Bagnardi V, Gandini S. Vitamin D deficiency and mortality risk in the general population: a meta-analysis of prospective cohort studies. Am J ClinNutr 2012; 95:91-100.

12. Rude R K, Wagner CL, Greer FR. Prevention of rickets and vitamin $\mathrm{D}$ deficiency in infants, children, and 
adolescents. Pediatrics. 2015; 122:114252.

13. Aghajafari F, Nagulesapillai T, Ronksley PE, Tough SC, O'Beirne M, Rabi DM. Association between maternal serum 25hydroxyvitamin D level and pregnancy and neonatal outcomes: systematic review and meta-analysis of observational studies. BMJ 2013; 346:1169. 